\title{
Effect of Ultrasonic Treatment on Radon Exhalation from Porous Media: An Experimental Case Study
}

\author{
Ling-feng Xie ${ }^{1,2}$, Shu-liang Zou ${ }^{1,3}$, Xiang-yang $\mathrm{Li}^{1,2}$, Chang-shou Hong ${ }^{1,2, * \mathbb{C}}$, Hong Wang ${ }^{1}$, \\ Zi-qi Cai ${ }^{1}$, Ming Li ${ }^{1}$, Shuai Zhang ${ }^{1}$ and Jing-fan Yuan ${ }^{1}$ \\ 1 School of Environment and Safety Engineering, University of South China, Hengyang 421001, China; \\ 201210210005@usc.edu.cn (L.-f.X.); zoushuliang@usc.edu.cn (S.-1.Z.); 430005773240@usc.edu.cn (X.-y.L.); \\ 14100045@usc.edu.cn (H.W.); 201523611052@usc.edu.cn (Z.-q.C.); 15100010@usc.edu.cn (M.L.); \\ zscsy1993@163.com (S.Z.); 201721620654@usc.edu.cn (J.-f.Y.) \\ 2 Hunan Province Engineering Technology Research Center of Uranium Tailings Treatment, \\ Hengyang 421001, China \\ 3 Hunan Provincial Key Laboratory of Emergency Safety Technology and Equipment for Nuclear Facilities, \\ Hengyang 421001, China \\ * Correspondence: 360003802790@usc.edu.cn
}

Received: 28 May 2018; Accepted: 20 August 2018; Published: 24 August 2018

\begin{abstract}
Radon is internationally recognized as one of the seven seismic precursors. A self-assembly ultrasonic generator and experimental apparatus for radon measurement were utilized to explore the radon exhalation regularities of water-bearing porous media under different ultrasonic intensities. The experimental results showed that there was a coupling relationship among radon exhalation rate, moisture content, and ultrasonic frequency. With the increase of the frequency of the ultrasonic wave, its effect on the promotion of radon exhalation rate was found to be a more obviously positive linear correlation. The radon exhalation rate, which could climb to a maximum value of $0.179 \mathrm{~Bq} \cdot \mathrm{m}^{-2} \cdot \mathrm{s}^{-1}$ in a naturally air-dried sample, increased at first and then decreased along with increased moisture content. Moreover, this study found that the ultrasonic wave had the most remarkable promoting effects on the radon exhalation rate of porous media with high moisture content, and there is a positive linear correlation between the growth rate of the radon exhalation rate and moisture content. The experimental results could provide a beneficial reference for the continual monitoring of radon in a seismically active belt and an explanation of radon anomalies; however, the proposed experimental model was simplified, so further insights are strictly required for a reliable correlation with the real monitoring of radon in a seismically active belt.
\end{abstract}

Keywords: water-bearing porous media; ultrasonic effect; radon exhalation rate; radon earthquake precursor

\section{Introduction}

Radon is one of the sensitive components of subsurface fluid for reflecting earthquakes, and a radon anomaly is internationally recognized as one of the seven seismic precursors [1]. Ulomov and Mavashev [2] found the concentration of radon in a deep well in Tashkent changed significantly before the 1966 Tashkent earthquake. Subsequently, many scholars also discovered the pre-earthquake phenomenon of radon anomalies [3-6]. Nowadays, the radon earthquake precursor is an important research direction for the field of earthquake prediction, and the monitoring of radon is one of the earthquake-related research projects that has been observed for the longest time and studied to the greatest extent. In China, the radon earthquake precursor plays a quite important part in seismic analysis and earthquake prediction [7]. 
The frequency band of acoustic emissions caused by fault creeping or microfracturing before an earthquake is sufficiently wide and contains an ultrasonic vibration with the frequency from a few 10s of kilohertz to 100 kilohertz, as well as acoustic vibrations and seismic waves with lower frequencies [8-10]. In the aftershock region of Tangshan, Hebei Province, an ultrasonic signal with the frequency of $40 \mathrm{kHz}$ was recorded [11]. Therefore, whether there is an internal relation between preseismic acoustic emissions and preseismic radon anomalies has attracted many scholars' attention. In 1977, А. Н. Султанходжаев [12] first proposed an ultrasonic mechanism of the radon seismic precursor, and the relative experiment carried out by him validated that most gaseous molecules of radon in rock pores were in the adsorption state, while the adsorptive power would be weakened under ultrasonic treatment. Then, the adsorbed radon transformed to a free state and exhaled to the surrounding space by diffusion. Feng et al. [13] conducted research on radon exhalation of artificial rocks under the influence of ultrasonic vibrations and remarkable variations of microcracks of the rocks were found, which proved there was an essential relation between radon anomalies exhaling from rocks and microcracks in the rocks caused by the ultrasonic effect. Currently, research on the mechanism of radon exhalation under ultrasonic effect in water-bearing porous media has not yet been reported.

The seismically active zones are widely distributed in land area of China, and the hydrogeological conditions in different regions vary from one to another due to differences in frost, rainfall, human factors, and so on, which cause rocks (or porous media) in each region to be within different states of water saturation $[14,15]$. In order to ascertain the mechanism of the radon seismic precursor under different hydrogeological conditions, a self-developed experimental apparatus for radon measurement with the effect of ultrasonic vibration was utilized on the basis of laboratory experiments to explore the radon exhalation regularities of water-bearing porous media.

\section{Material and Methods}

\subsection{Sample Preparation and Basic Properties Determination}

Ultrasonic propagation is strongly influenced by textural and compositional features of porous media [16]. Therefore, the uranium mill tailings taken from a uranium tailings pond in southern China were employed as one of the major raw materials. Its radium content was measured by adopting the scintillation chamber method $[17,18]$, and the measuring result was $7.98 \times 10^{3} \mathrm{~Bq} \cdot \mathrm{kg}^{-1}$. The tailings sieved by an 8-mesh sieve were well mixed with cement in three same self-made molds according to the mass proportion of 10:3, and a moderate quantity of water was slowly poured into the mixture. The molding samples (numbered as SPL 1, 2 and 3, respectively) were prepared as cubic shapes with a side length of $150 \mathrm{~mm}$, and a hollow circular cylinder with a diameter of $75 \mathrm{~mm}$ was in the middle of two opposite planes of the cubic samples (see Figure 1).

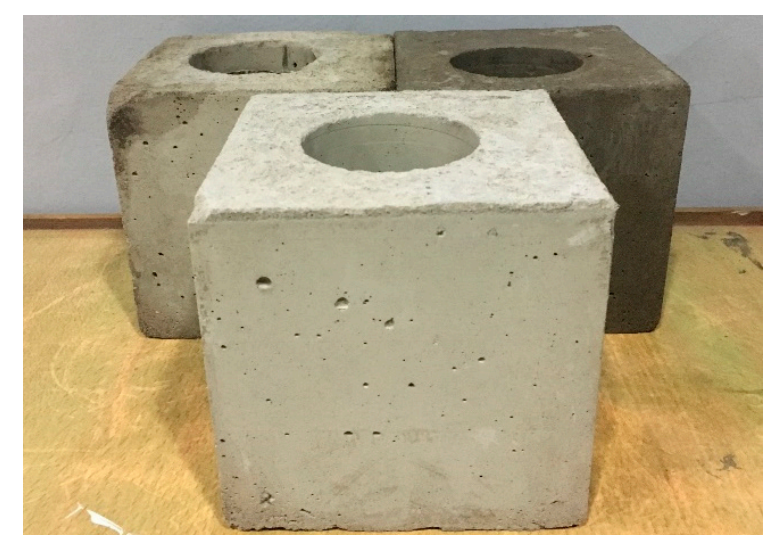

Figure 1. The molding samples. 
SPL 1 was dried at $110 \pm 1{ }^{\circ} \mathrm{C}$ till a constant weight was obtained in a drying oven, and then it was let to naturally cool to room temperature. SPL 2 was soaked in water until it was saturated and was then naturally air-dried. SPL 3 was soaked in water until it was saturated (soaked for at least 12 h). SPL 1-3 were named dry sample, air-dried sample, and saturated sample, respectively. The basic properties of the samples are shown in Table 1. In particular, the dose equivalent rate was measured by a professional detector, RM250 gamma meter, produced by Shanghai Chaoqi Electronic Co., Ltd., China. The density and porosity were respectively determined by the weighing method and mercury intrusion analytical method [19-21]. Both sides of each sample's hollow circular cylinder were sealed using two PVC boards as well as neutral glue. Then, the hollow part was used as a radon collection space. In order to avoid variations in water content and radon escape, aluminum foil was utilized to cover the surface of each sample.

Table 1. The basic properties of the prepared samples.

\begin{tabular}{|c|c|c|c|c|c|c|}
\hline Sample & $\begin{array}{l}\text { Weight } \\
\text { (g) }\end{array}$ & $\begin{array}{l}\text { Density } \\
\left(\mathrm{g} \cdot \mathrm{cm}^{-3}\right)\end{array}$ & $\begin{array}{l}\text { Porosity } \\
(\%)\end{array}$ & $\begin{array}{l}\text { Water Content } \\
(\%)\end{array}$ & $\begin{array}{l}\text { Radium Content } \\
\left(\mathrm{Bq} \cdot \mathrm{kg}^{-1}\right)\end{array}$ & $\begin{array}{c}\text { Dose Equivalent } \\
\text { Rate }\left(\mu \mathrm{Sv} \cdot \mathrm{h}^{-1}\right)\end{array}$ \\
\hline SPL 1 & 5017.1 & 2.24 & 9.62 & 0 & $6.01 \times 10^{3}$ & 1.01 \\
\hline SPL 2 & 5363.4 & 2.17 & 9.47 & 6.83 & $6.01 \times 10^{3}$ & 1.04 \\
\hline SPL 3 & 5739.1 & 2.22 & 9.55 & 14.37 & $6.01 \times 10^{3}$ & 1.03 \\
\hline
\end{tabular}

\subsection{Measurement of Radon Exhalation Rate under Ultrasonic Treatment}

\subsubsection{Description of Experimental Apparatus}

The experiments were carried out by use of a self-assembly experimental apparatus that mainly consisted of an ultrasonic generator, a thermostatic water bath, a pump, and a calibrated RAD 7 radon monitor (see Figure 2). Engine oil was utilized as the couplant for eliminating the adverse effect of air between the ultrasonic generator's probes and the sample. The ultrasonic generator was a KMD-M1, and its rated voltage and ultrasonic frequencies were $220 \mathrm{~V}$ and $10-60 \mathrm{kHz}$, respectively. Moreover, the power of the ultrasonic generator contained six grades, namely, 10, 20, 30, 40, 50, and $60 \mathrm{kHz}$.

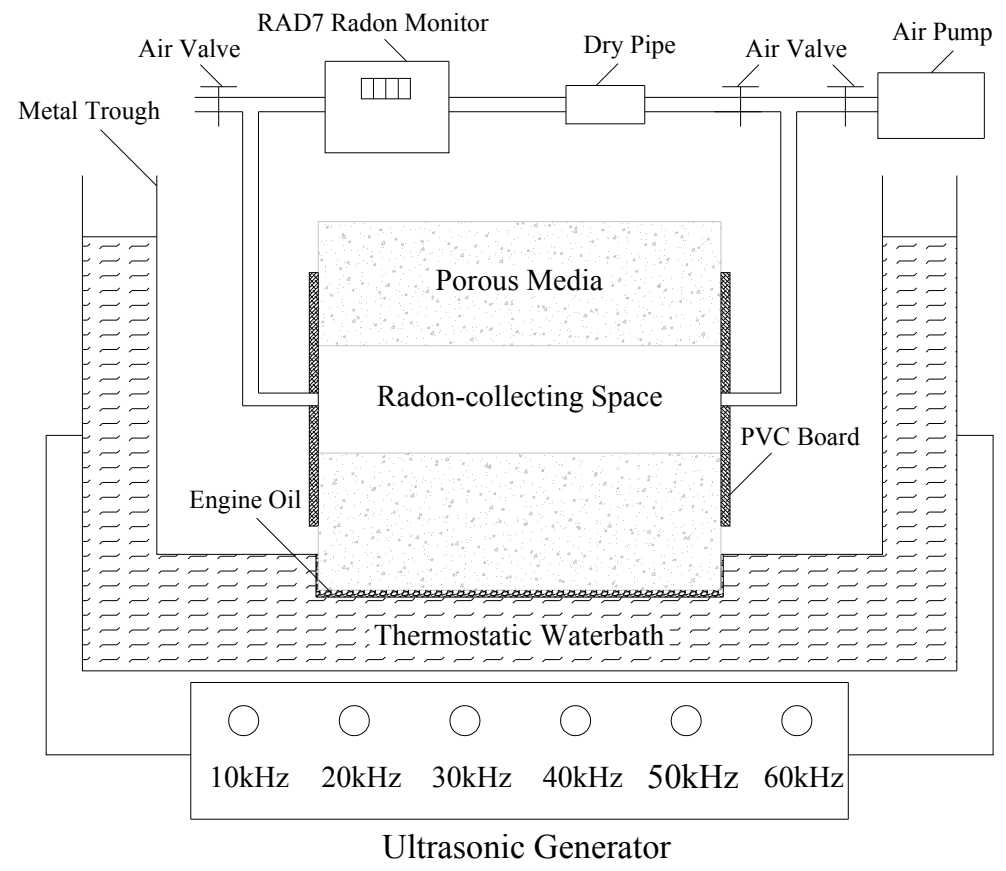

Figure 2. Schematic diagram of the experimental apparatus. 


\subsubsection{Experimental Procedure}

The procedure of each experiment was as follows:

(1) Check the gas-tightness of the apparatus, and never begin an experiment until the tightness meets requirement.

(2) Place the flume inlayed with the prepared sample in the thermostatic water bath in preparation for ultrasonic treatment.

(3) Each experiment was divided into three experimental units (30 min per experimental unit), namely, the pre-ultrasonic treatment (Pre-UT) unit, under ultrasonic treatment (Under-UT) unit, and post-ultrasonic treatment (Post-UT) unit. Continually monitor the radon concentration of each experimental unit, for which the monitoring data were denoted as $A_{1}, A_{2}$, and $A_{3}$.

(4) After completing the experiments, switch off all the devices and seal up the samples for $24 \mathrm{~h}$ for next experiments.

The total time for procedures 1-4 was $27 \mathrm{~h}$. For the purpose of obtaining accurate measuring data of the radon concentration in the collection space, reducing the impact of ambient humidity was imperative. Therefore, these experiments were conducted from 8 a.m. to 8 p.m., from September 2016 to October 2016. Additionally, samples' temperature variations during the experiments were recorded.

\section{Results and Discussion}

\subsection{Radon Exhalation Characteristics for Pre-UT Unit}

The samples were sealed for $24 \mathrm{~h}$ before each experiment. The radon concentration of each sample was continually monitored, and radon exhalation rates (see Figure 3) were obtained by using the calculation method proposed by Zhang et al. [22].

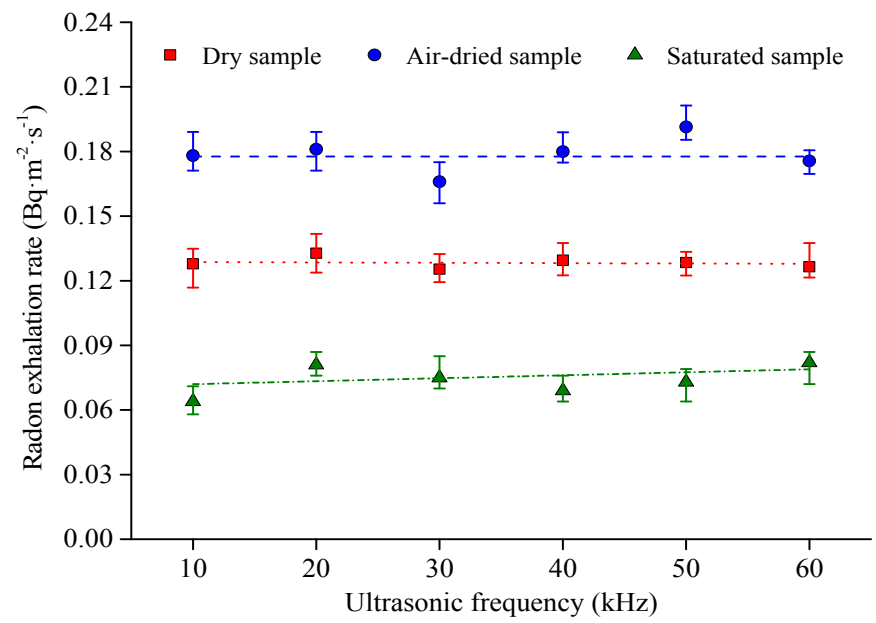

Figure 3. Radon exhalation rates of samples for the pre-ultrasonic treatment (Pre-UT) unit.

According to Figure 3, with respect to any of the six experiments for each sample, the values of the radon exhalation rate were basically identical. In particular, the radon exhalation rate of the sample with the moisture content of $6.83 \%$ (i.e., SPL 2) was $0.179 \mathrm{~Bq} \cdot \mathrm{m}^{-2} \cdot \mathrm{s}^{-1}$, which was the maximum value. In terms of SPL 1 and SPL 3, their radon exhalation rates were 0.128 and $0.074 \mathrm{~Bq} \cdot \mathrm{m}^{-2} \cdot \mathrm{s}^{-1}$, respectively. Additionally, the experimental results showed that the radon exhalation rates of these samples were approximately equal after being sealed and carefully placed. This agrees well with previous research results [12].

The weight of each sample, after finishing any experiment, was measured. The results indicated that the variations of the pre- and post-experiment's weight fluctuated between 1 and $2 \mathrm{~g}$, which means 
that the moisture contents of the samples changed insignificantly during the implementation processes of any experiment. The radon exhalation rates under the experimental condition of different moisture contents (Pre-UT unit) are shown in Figure 4. As shown in this figure, a concave shape was found with respect to the relationship between the radon exhalation rate and moisture content. With the increase of moisture content, the sample's radon exhalation rate increased. When the moisture content was $7 \%$ or so, the radon exhalation rate reached the maximum value; however, the radon exhalation rate was declining relatively sharply with a rising of moisture content. This may be explained based on the hypothesis that lower moisture content promotes the exhalation process of radon from porous media, while when the moisture content reached a certain value, with the increase of this parameter, the radon exhalation would be restrained. This is consistent with previous research conclusions [23,24].

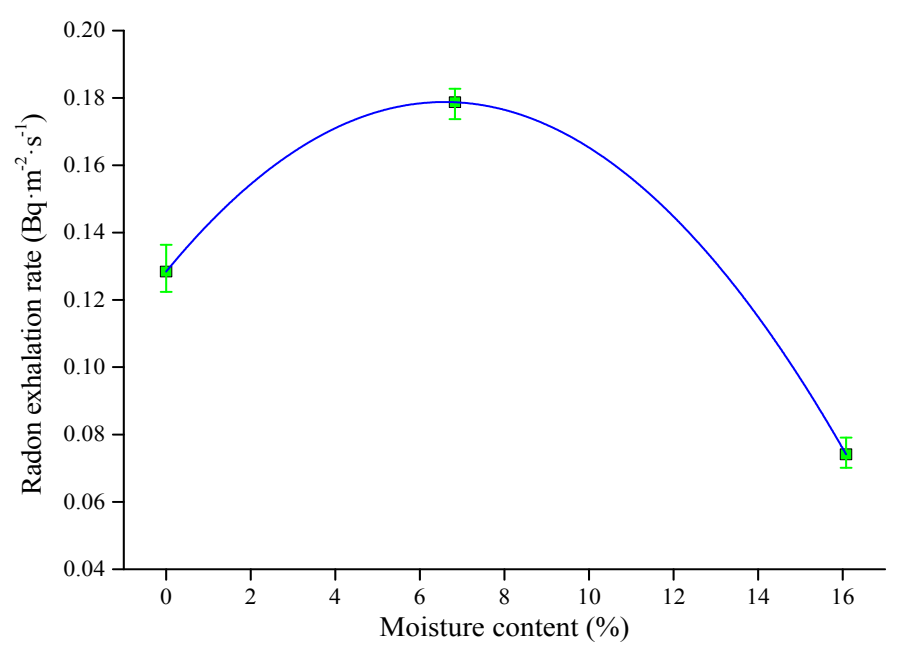

Figure 4. Effect of moisture content on radon exhalation rate.

\subsection{Radon Exhalation Characteristics for Under-UT Unit and Post-UT Unit}

Considering that heating effect was remarkable under ultrasonic action, those experiments of the Under-UT and Post-UT units were strictly in temperature-controlled conditions. The measuring data of all the samples' temperature rise were 2 to $3{ }^{\circ} \mathrm{C}$. Thus, the impact of the heating effect of ultrasonic action on a sample's radon exhalation rate was ignored. The continuous monitoring of radon concentrations of each sample for the Under-UT and Post-UT units $\left(A_{1}, A_{2}\right)$ were conducted, and based on these monitoring values, the radon exhalation rate of each sample was obtained (see Figure 5).

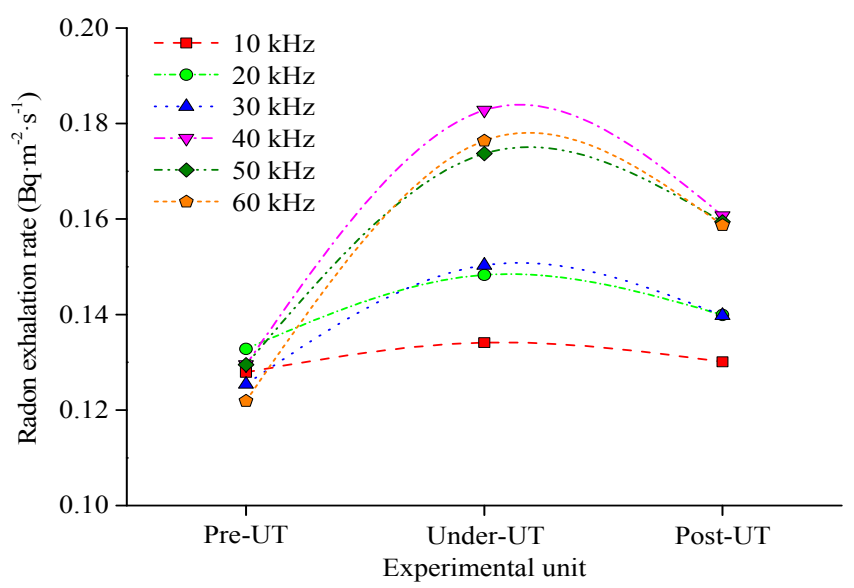

(a)

Figure 5. Cont. 


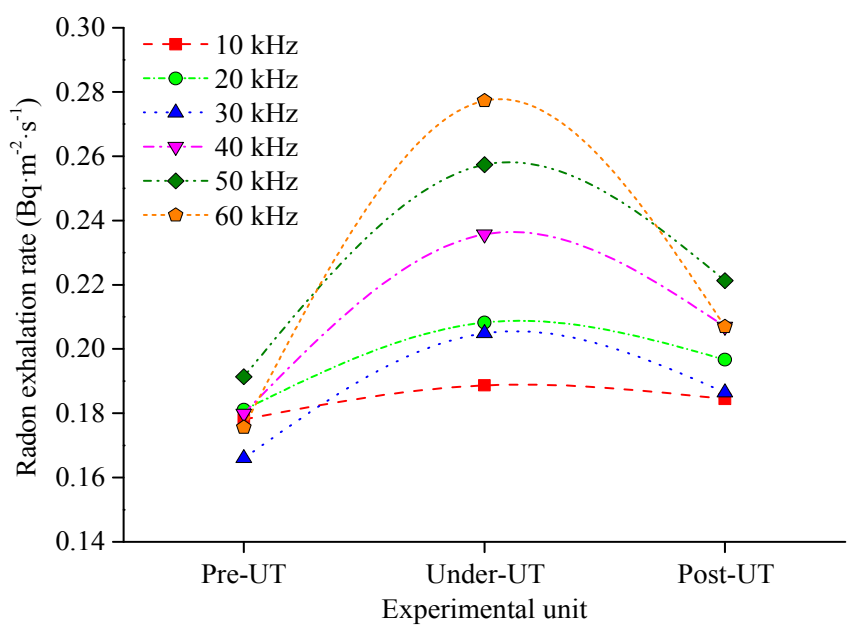

(b)

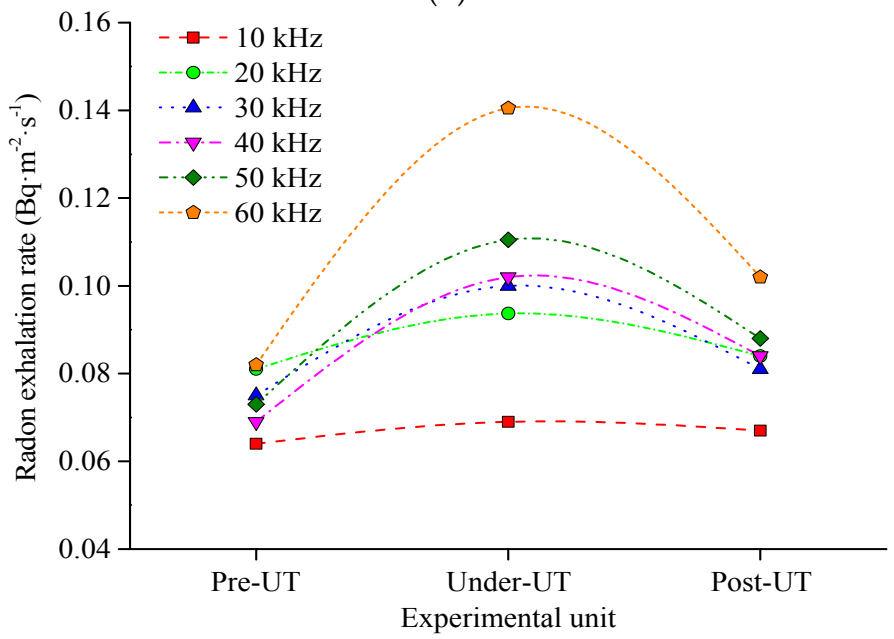

(c)

Figure 5. Effect of ultrasonic treatment on radon exhalation rate. (a) Dry sample; (b) Air-dried sample; (c) Saturated sample.

Within $30 \mathrm{~min}$ after stopping ultrasonic action, the radon exhalation rates of all the samples slightly decreased but were still higher than those of the Pre-UT unit. Moreover, each sample's radon exhalation rate was on the same level before the treatment of ultrasonic action. This distinctly indicated that there was a hysteretic effect of ultrasonic treatment on radon exhalation. The experimental results also indicated that the samples' radon exhalation rates to some degree increased when they were in the status of ultrasonic action, and the growth rate continuously increased along with the increase of ultrasonic frequency (see Figure 6).

As shown in Figure 6, different samples exhibited different growth rates with respect to radon exhalation rate when they were treated by the same frequency. In detail, the growth rate of SPL 3's radon exhalation rate (under ultrasonic treatment with frequencies of 10, 20, 30, 40, 50, or $60 \mathrm{kHz}$ ) was $71.43 \%$, followed by SPL 2 and SPL 1 (57.91\% and 44.67\%, respectively). Accordingly, the effect of ultrasonic treatment on the growth rate of the radon exhalation rate with respect to the sample with higher moisture content would be more remarkable. 


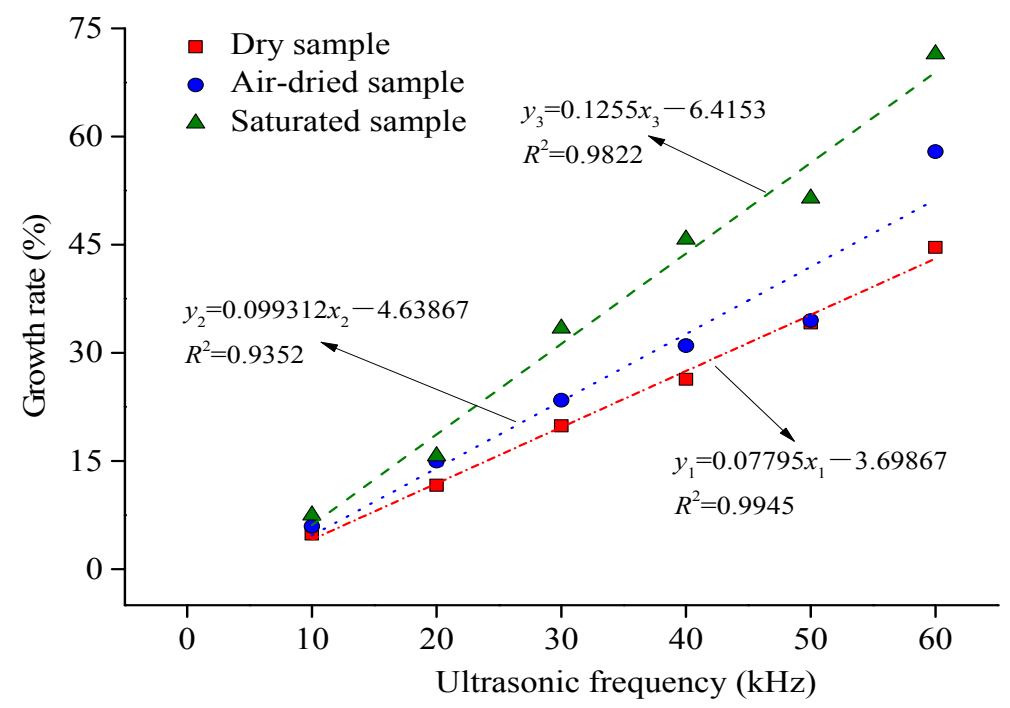

Figure 6. Effect of ultrasonic treatment on the growth rate of the radon exhalation rate.

\section{Conclusions}

In this paper, the mechanisms of radon exhalation in porous media with different moisture contents were studied utilizing a self-designed ultrasonic-considered radon monitor apparatus. The study aimed to explore the regularities of the radon earthquake precursor under different hydrogeological conditions. The conclusions drawn are as follows:

(1) The radon exhalation rate of porous media to some extent increased under the treatment of ultrasonic action, and a positive correlation was discovered between the growth rate of the radon exhalation rate and ultrasonic frequency.

(2) The radon exhalation rate of porous media slightly decreased after ceasing ultrasonic treatment, however, it would increase to the initial value when the sample was sealed for $24 \mathrm{~h}$. That is to say, the radon exhalation capacity was insignificantly affected by ultrasonic action.

(3) The radon exhalation rate of the air-dried sample was greater than those of the dry and saturated samples, and the water-saturated sample exhibited the lowest radon exhalation rate. The exhaling of radon from porous media was greatly affected by its moisture content.

(4) The porous media with increased moisture content favored the conduction of ultrasonic waves; that is, the growing effect of ultrasonic treatment on the radon exhalation rate of the water-saturated sample was relatively prominent.

(5) The variant feedback mechanisms of ultrasonic treatment on radon exhaling from those porous media with different moisture contents were found in this study as well as in the field of radon monitoring in different regions (the regions with various hydrogeological conditions). Therefore, the strengthening of radon monitoring in different regions could provide useful references for earthquake prediction. Nevertheless, considering that the proposed experimental model in this study was simplified, further insights are therefore required for a reliable correlation with the real monitoring of radon concentrations in a seismically active belt.

Author Contributions: L.-f.X. and S.-1.Z nominated the conception; X.-y.L. and C.-s.H. put forward the method; L.-f.X., C.-s.H. and H.W. investigated the whole process of paper; L.-y.X. provided the resources; C.-s.H., Z.-q.C., M.L. and S.Z. completed the data management; C.-s.H. and L.-f.X. finished the original draft; C.-s.H. and J.-f.Y. wrote the review and edited the paper; S.-1.Z supervised the progress; X.-y.L. supervised and provided the project support.

Funding: This research was funded by the National Natural Science Foundation of China (Grant No. 11475081). 
Acknowledgments: We gratefully acknowledge the assistance of Professor Xinghuo Zhou in improving the experiment scheme and enlightening discussions. We also thank the anonymous reviewers for their valuable comments that not only help us with the improvement of our manuscript, but suggest some neat ideas for future studies.

Conflicts of Interest: The authors declare no conflicts of interest.

\section{References}

1. Friedmann, H. Radon in earthquake prediction research. Radiat. Prot. Dosim. 2012, 149, 177-184. [CrossRef] [PubMed]

2. Ulomov, V.I.; Mavashev, B.Z. A precursor of a strong tectonic earthquake. Dokl. Akad. Sci. USSR Earth Sci. Sect. 1967, 176, 9-11.

3. King, C.Y. Impulsive radon emanation on a creeping segment of the San Andreas fault, California. Pure Appl. Geophys. 1984, 122, 340-352. [CrossRef]

4. Virk, H.S.; Singh, B. Radon anomalies in soil-gas and groundwater as earthquake precursor phenomena. Tectonophysics 1993, 227, 215-224. [CrossRef]

5. Walia, V.; Virk, H.S.; Bajwa, B.S.; Sharma, N. Relationships between radon anomalies and seismic parameters in N-W Himalaya, India. Radiat. Meas. 2003, 36, 393-396. [CrossRef]

6. Ghosh, D.; Deb, A.; Sengupta, R. Anomalous radon emission as precursor of earthquake. J. Appl. Geophys. 2009, 69, 67-81. [CrossRef]

7. Zhang, S.M.; Shu, Y.L.; Wang, X.; Lin, J.Z.; Peng, Y.Z. Primary research on relationship between gas radon in Zhouzhi well and earthquake in neighboring regions. J. Catastrophol. 2006, 21, 83-86.

8. Paparo, G.; Gregori, G.P.; Coppa, U.; De Ritis, R.; Taloni, A. Acoustic Emission (AE) as a diagnostic tool in geophysics. Ann. Geophys. 2002, 45, 401-416.

9. Larionov, I.A.; Marapulets, Y.V.; Shevtsov, B.M. Features of the Earth surface deformations in the Kamchatka peninsula and their relation to geoacoustic emission. Solid Earth Discuss. 2014, 6, 2401-2422. [CrossRef]

10. Marapulets, Y.V. High-frequency acoustic emission effect. Bull. Krasec Phys. Math. Sci. 2015, 10, 39-48.

11. Zhang, S.D.; Liu, L.Q.; Liu, P.X.; Chen, G.Q. Observations on ultrahigh frequency earthquake signal. Seismol. Geol. 2014, 36, 230-242.

12. Султанходжаев, А.Н. О Причинах аномального поведения радона в подземных водах сейсмоактивных районов. Узбекский геологицеский журнал 1977, 2, 29-37. (In Russian)

13. Feng, W.; Wang, Y.C.; Deng, Y.R.; Hou, Y.Z. Experimental study on radon emanation of saturated rock under ultrasonic vibration. Seismol. Geol. 1981, 3, 1-7.

14. Chen, L.; Fu, H.; Zou, J.M. Hydrogeological analysis of regional groundwater in Jianshui abnormal macro-analysis. J. Seismol. Res. 2010, 33, 176-182.

15. Yang, G.G.; Yang, Y.Z.; You, Z.; Zhang, X.Y. The temporal and spatial distribution pattern of earthquake disaster in Chinese mainland. Adv. Earth Sci. 2011, 26, 548-555.

16. Arizzi, A.; Martínez-Martínez, J.; Cultrone, G. Ultrasonic wave propagation through lime mortars: An alternative and non-destructive tool for textural characterization. Mater. Struct. 2013, 46, 1321-1335. [CrossRef]

17. Girault, F.; Perrier, F. Measuring effective radium concentration with large numbers of samples. Part I-Experimental method and uncertainties. J. Environ. Radioact. 2012, 113, 177-188. [CrossRef] [PubMed]

18. Girault, F.; Perrier, F. Measuring effective radium concentration with large numbers of samples. Part II-General properties and representativity. J. Environ. Radioact. 2012, 113, 189-202. [CrossRef] [PubMed]

19. Calcaterra, D.; Cappelletti, P.; Langella, A.; Collella, A.; De Gennaro, M. The ornamental stones of Caserta province: The Campanian Ignimbrite in the medieval architecture of Casertavecchia. J. Cult. Herit. 2004, 5, 137-148. [CrossRef]

20. Izzo, F.; Arizzi, A.; Cappelletti, P.; Cultrone, G.; De Bonis, A.; Germinario, C.; Graziano, S.F.; Grifa, C.; Guarino, V.; Mercurio, M.; et al. The art of building in the Roman period (89 B.C.-79 A.D.): Mortars, plasters and mosaic floors from ancient Stabiae (Naples, Italy). Constr. Build. Mater. 2016, 117, 129-143. [CrossRef] 
21. Grifa, C.; Germinario, C.; De Bonis, A.; Mercurio, M.; Izzo, F.; Pepe, F.; Bareschino, P.; Cucciniello, C.; Monetti, V.; Morra, V.; et al. Traditional brick productions in Madagascar: From raw material processing to firing technology. Appl. Clay Sci. 2017, 150, 252-266. [CrossRef]

22. Zhang, L.; Lei, X.; Guo, Q.J.; Wang, S.Q.; Ma, X.H.; Shi, Z.L. Accurate measurement of the radon exhalation rate of building materials using the closed chamber method. J. Radiol. Prot. 2012, 32, 315-323. [CrossRef] [PubMed]

23. Rahman, S.; Ghauri, B. Effect of moisture on the radon exhalation rate from soil, sand and brick samples collected from NWFP and FATA, Pakistan. Radiat. Prot. Dosim. 2008, 130, 172-177. [CrossRef] [PubMed]

24. Faheem, M. Radon exhalation and its dependence on moisture content from samples of soil and building materials. Radiat. Meas. 2008, 43, 1458-1462. [CrossRef]

(C) 2018 by the authors. Licensee MDPI, Basel, Switzerland. This article is an open access article distributed under the terms and conditions of the Creative Commons Attribution (CC BY) license (http:/ / creativecommons.org/licenses/by/4.0/). 